\title{
Contribution to the Characterization Study of the Surface Indices of the Lotshi Block and Its Surroundings in the Coastal Basin of Congo
}

\author{
Bruno Deko Oyema1, Dominique Wetshondo Osomba², Bavon Diemu Tshiband1, \\ Patrick Lokata Ediho", ${ }^{1,3}$ Jean-Piére Kalay Kut ${ }^{1}$, Jean Ondontshia Nkoyi1, \\ Link Bukasa Muamba1, Joël Kabesa Kilungu1 \\ ${ }^{1}$ Exploration and Production Department, Faculty of Oil, Gas and Renewable Energies, University of Kinshasa, Kinshasa, \\ Democratic Republic of the Congo \\ ${ }^{2}$ Geoscience Department, Faculty of Sciences, University of Kinshasa, Kinshasa, Democratic Republic of the Congo \\ ${ }^{3}$ Centre de Recherche en Géophysique (CRG), Kinshsa, Democratic Republic of the Congo \\ Email: brunodeko@unikin.ac.cd,brunosdeko@gmail.com
}

How to cite this paper: Oyema, B.D., Osomba, D.W., Tshiband, B.D., Ediho, P.L., Kut, J.-P.K., Nkoyi, J.O., Muamba, L.B. and Kilungu, J.K. (2022) Contribution to the Characterization Study of the Surface Indices of the Lotshi Block and Its Surroundings in the Coastal Basin of Congo. Open Journal of Yangtze Gas and Oil, 7, 84-100. https://doi.org/10.4236/ojogas.2022.71006

Received: November 21, 2021

Accepted: January 27, 2022

Published: January 30, 2022

Copyright $\odot 2022$ by author(s) and Scientific Research Publishing Inc. This work is licensed under the Creative Commons Attribution International License (CC BY 4.0).

http://creativecommons.org/licenses/by/4.0/ (c) (i) Open Access

\begin{abstract}
The Lotshi block with an area of $506 \mathrm{Km}^{2}$, is located in the coastal basin in central Congo. It is between $12^{\circ} 31^{\prime}$ and $12^{\circ} 53^{\prime}$ east longitude and $05^{\circ} 33^{\prime}$ and $05^{\circ} 44^{\prime}$ south latitude. As part of this research, we carried out geological observations in the field, and sampled rocky materials in sites of petroleum interest in the Lotshi Block and surroundings in order to contribute to the understanding of the petroleum geology of this block, more particularly of its petroleum system. The samples brought back from the field were subjected to microscopic, mineralogical, (DRX), chemical (XRF) analyses and to the extraction of the hydrocarbon binder contained therein at the laboratories of ULG (Belgium), CRGM and OR in Kinshasa. The results obtained are summarized as follows: 1) Mineralogically: quartz, $\mathrm{k}$-feldspar, plagioclase, calcite and dolomite are the dominant minerals in the samples analyzed; 2) Lithologically: two lithofacies (quartz sandstone and carbonate sandstone); 3) On the petroleum level: the sandstone rock of Lotshi and its surroundings are impregnated with hydrocarbons. It contains between $12 \%$ and $25 \%$ of hydrocarbon binder.
\end{abstract}

\section{Keywords}

Characterization, Indices, Lotshi Block

\section{Introduction}

Democratic Republic of the Congo has three sedimentary basins potentially rich 
in hydrocarbons of which only the coastal basin is in oil production qualified as marginal for an average flow of 25,000 bopd. This production comes from a tiny part of the total area of the basin which is $6000 \mathrm{~km}^{2}: 15,000 \mathrm{bbl} / \mathrm{d}$ from offshore $\left(1012 \mathrm{~km}^{2}\right)$ and $10,000 \mathrm{bbl} / \mathrm{d}$ from onshore $\left(426 \mathrm{~km}^{2}\right)$.

Thus, in the search for a solution to this low production, the D.R. Congo has carried out the block cutting of oil exploration of the ex-renderings of fina in Oshore of the coast basin for some years.

Allocated to the oil company Engulf, The Lotshi block with a surface area of $506 \mathrm{Km}^{2}$, results from this division and will be the subject of our contribution in the oil exploration work with surface geology, for the characterization of showings of hydrocarbons.

The characterization of rocks to define the petroleum system is essential in the exploration phase and the determination of indices are irrefutable arguments for continuing exploration in a sedimentary basin [1] [2], the objectives of the present research are the knowledge of the hydrocarbon indices, to determine the major lithofacies of the zone and to give the interest of these rocky materials impregnated with hydrocarbons.

\section{Environment, Materials and Methods}

\subsection{Environment}

Lemba is located on land on the Congolese coast (DRC), just east of the "exZaïrep" concession, currently operated by Perenco rep. It is bounded on the east by the plinth, to the south by the Congo River and to the west by the aforementioned concession. The northernmost point of the area is $5^{\circ} 00^{\prime} \mathrm{S}, 12^{\circ} 38^{\prime} \mathrm{E}$, its easternmost points are along the meridian $13^{\circ} 11^{\prime} \mathrm{E}$, and its westernmost point is $5^{\circ} 45^{\prime} \mathrm{S}$, $12^{\circ} 15^{\prime} \mathrm{E}$. Its approximate area is 4916 Square Kilometers ( 1.2 million acres).

There are three main pre-salt sub-basins: The Lemba depression (Lemba ditch) and the smaller Sintu and Malongo-Tshikoko depressions. These three depressions contain the Bucomazi bedrock [3].

The Lotshi block our study area is in the Lemba depression (Figure 1).

Below illustrates the structural map of three Presaliferous sub-basins.

Gaffney, Cline et al. [4] [5] estimated maximum sediment thicknesses of 7 - 10 $\mathrm{km}, 5 \mathrm{~km}$, and $3 \mathrm{~km}$, respectively for the Coast Basin offshore, the Coastal plain, and the Lemba study area.

Note that of all the commercial oil discoveries, none is part of the Lemba study area. However, several drilled wells have tested the formations there. We can cite the wells:

- Lindu-1: drilled in the Sintu Ditch, having tested the Chela interval;

- Kanga-1, Lindu-2, and Lindu-3: are drilled in the Sintu and Malongo-Tshikoko ditches, attempting to define the extent of the Lindu-1 discovery deposit;

- Zadikongo, Puela, and Forabola: are drilled in the Lemba ditch, and minor oil showings were encountered in the Chela formation, but the test was inconclusive; 


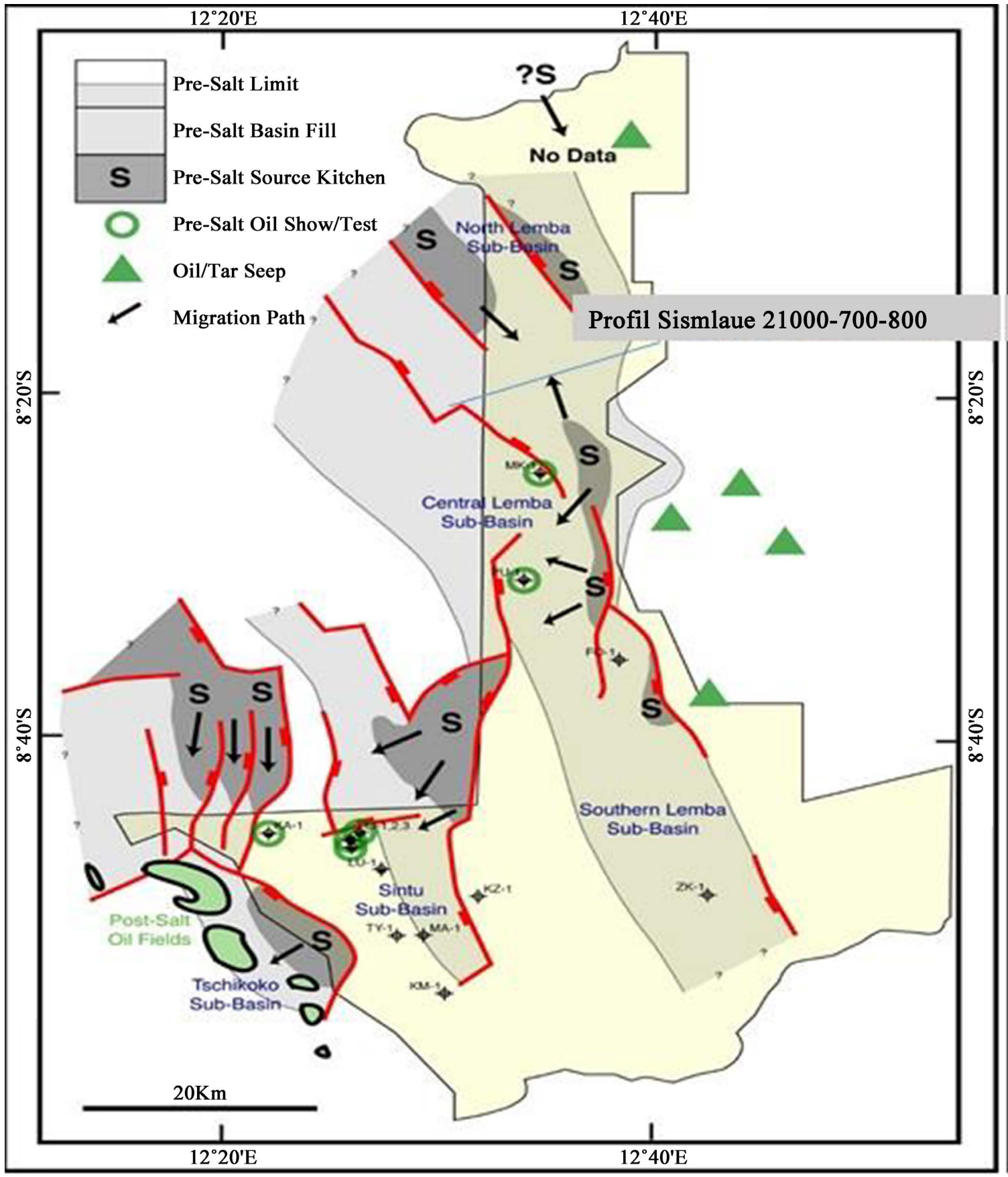

Figure 1. The structural map of three Presaliferous sub-basins.

- Makanga-1: tested the Chela, but still inconclusive.

At the end of the study by Conoco Zaire [6] six prospects were identified there from the interpretation of seismic data. These prospects are: Ndunda, Losthi, Yema, Nganzi, Bayingu, and Lindu Est.

In the post-2000s, the Lemba study area was subdivided into respective oil blocks, including Lotshi, Yema, Ndunda, Nganzi, Matamba Makanzi, and Mavuma. As you can see, some blocks have the names of prospects mentioned in the previous paragraph. 
Very recently, these blocks have been the subject of other exploration campaigns, carried out by the following operators: ENERGULF Congo Sarl, SOCO E \& P DRC, and SURESTREAM. But the drilling results from the Nganzi and Matamba Makanzi blocks did not reveal any oil discovery, the Lotshi blocks in our study area, Yema and Ndunda having not seen any drilling during these recent exploration campaigns [7] [8].

However, the discovery of the M'boundi field in the Republic of Congo, in 2004, is an extension of the Fossé Lemba; well before this discovery, another was reported in northern Cabinda.

No finds can be found in the Lemba Ditch, or even in the entire Lotshi study area. While the extension of this Ditch, reveals discoveries in North Cabinda, and in the Republic of Congo [9] [10].

Our study area is located in Kongo Central Province, Lotshi Block with an area of $506,752 \mathrm{~km}^{2}$. It is between $12^{\circ} 31^{\prime}$ and $12^{\circ} 53^{\prime}$ East longitude and $05^{\circ} 33^{\prime}$ and $05^{\circ} 44^{\prime}$ South latitude. At the end of the study (3), six prospects were identified there from the interpretation of seismic data. These prospects are: Ndunda, Losthi, Yema, Nganzi, Bayingu, and Lindu Est (Figure 2).

The observation stations made in the field are listed in the various stations of the Lotshi block and schematically summarized on the map in (Figure 3).

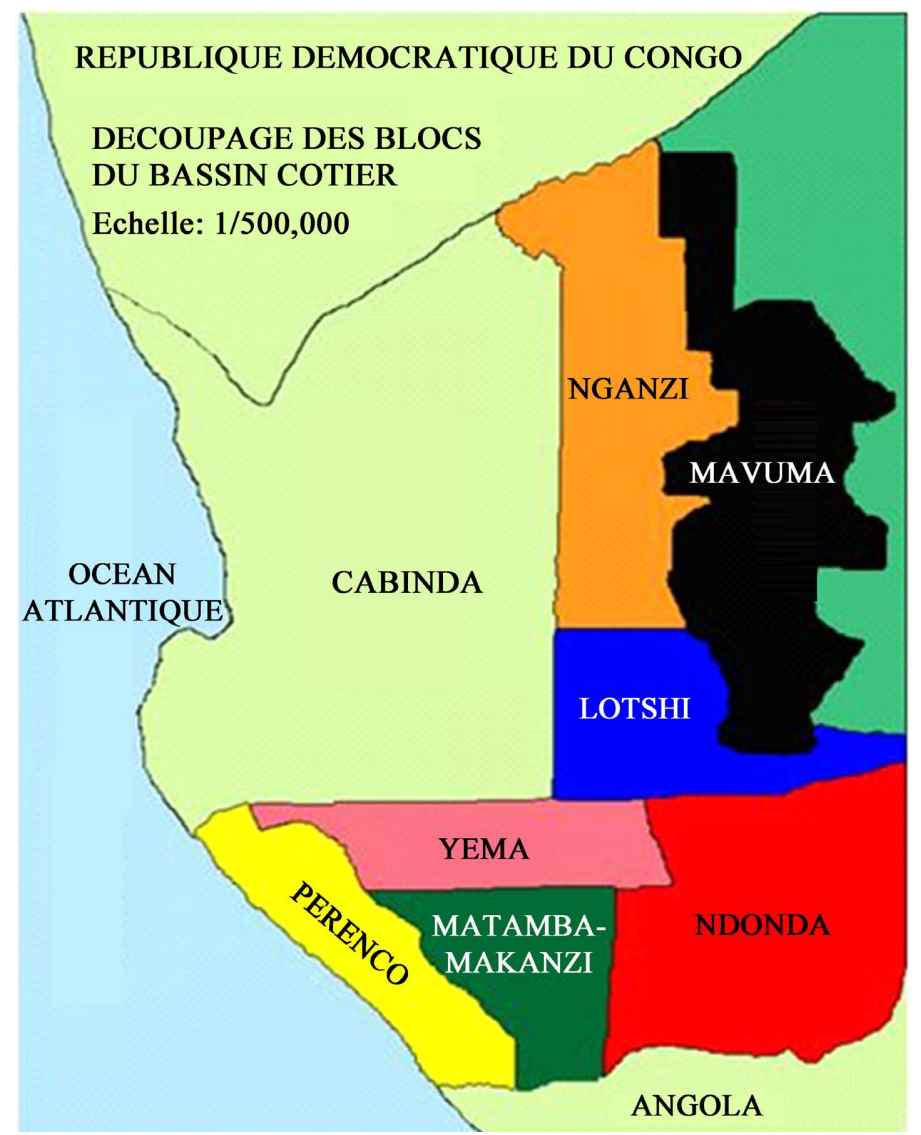

Figure 2. Maps locating the LOTSHI Block, and the other block open to exploration in the coastal basin. 


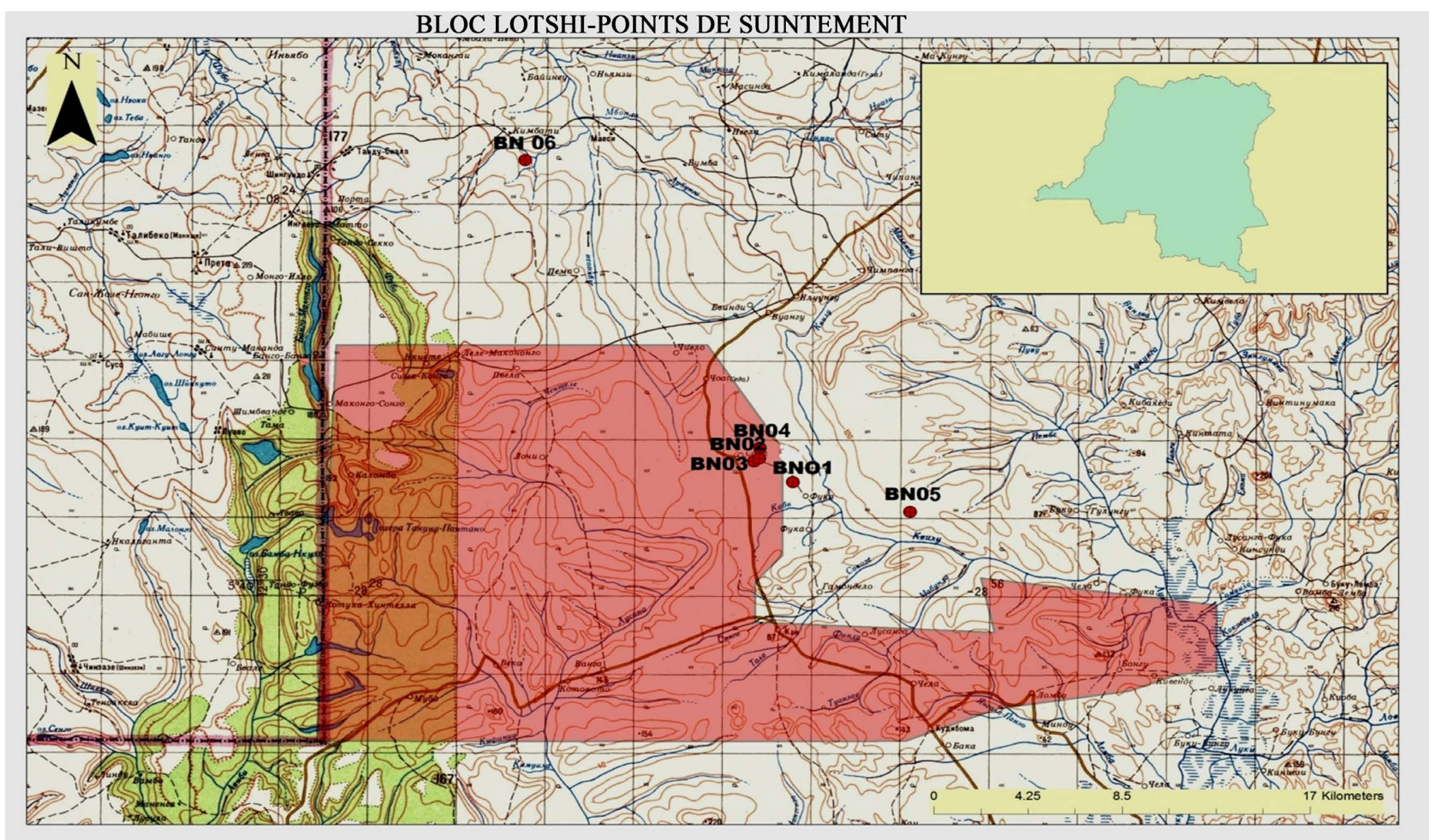

Figure 3. Sampling map in the Lotshi block.

\subsection{Materials}

The main materials used in this work for treatment, without which we would not achieve our goals, are:

- GPS for taking geographic coordinates in order to geo-reference the stations on the topographic background;

- The geologists' hammers to break the various outcrops on the ground in order to appreciate the color, the facies, the texture and to collect the rock samples;

- Geological compasses for taking direction and dip measurements in order to orient the plans and lineations;

- Cameras for taking pictures of certain geologically interesting aspects;

- Magnifying glasses for enlargement;

- The markers to number the samples, indicate the polarity;

- The use of software made it possible to process the data;

- A polarizing microscope for the microscopic description of rocks.

\subsection{Methods}

We proceeded by the bibliographic study (in the state services of the country) of work relating to the geology of Kongo Central and more particularly of the Lotshi Block.

Then, we carried out a geological survey on the ground in order to sample the surface showings and the geological formations that outcrop. 
Finally, we sent the samples to Europe (Belgium), for the following analyzes:

- X fluorescence, to know the chemical elements found in our samples;

- X-ray diffraction, in order to know the minerals constituting our samples.

And locally in Kinshasa, at the Geological and Mining Research Center and at the Road Office laboratory, for the following analyzes:

- the making of thin sections;

- geochemistry (volumetry and spectrophometry);

This methodology allowed us to carry out the characterization of the surface showings of the Lotshi Block and its surroundings.

\section{Data}

We present the data collected in the field during our geological survey. These data relate to the geological formations observed in the banks and beds of the rivers, in the cliffs and along the tracks. A single cut perpendicular to the direction of the layers was made in order to cut as much as possible the different layers of our study area, namely:

Cross-section going from the Mbuluzi River within the MBEMBIKA villa to the Timazimazi River in the Sekulado village, oriented from the NE side to the SW.

\subsection{Field Observations}

The observations made in the field are shown in Table 1, and Figure 2 shows pictures of some samples. The surface geology which has been known since 1925 as the only method for the search for structural traps [11], these samples are collected to characterize the surface indices.

Table 1. Presentation of field data.

\begin{tabular}{|c|c|c|c|c|}
\hline \multirow{2}{*}{$\mathrm{N}^{\bullet}$ of stations } & \multicolumn{3}{|c|}{ Geographical coordinates } & \multirow{2}{*}{ Structural measures } \\
\hline & Longitudes & Latitudes & Altitudes & \\
\hline BN 01 & $12^{\circ} 42^{\prime} 8.4^{\prime \prime}$ & $5^{\circ} 36^{\prime} 45.5^{\prime \prime}$ & $110 \mathrm{~m}$ & $\begin{array}{c}\text { Strat plan. } \\
\text { N115/22NE } \\
\text { N107/15NE }\end{array}$ \\
\hline BN 02 & $12^{\circ} 42^{\prime} 16.7^{\prime \prime}$ & $5^{\circ} 36^{\prime} 40.5^{\prime \prime}$ & $95 \mathrm{~m}$ & $\begin{array}{c}\text { Strat plan } \\
\text { N109/24NE }\end{array}$ \\
\hline BN 03 & $12^{\circ} 42^{\prime} 17^{\prime \prime}$ & $5^{\circ} 36^{\prime} 23^{\prime \prime}$ & $60 \mathrm{~m}$ & \\
\hline BN 04 & $12^{\circ} 43^{\prime} 5.3^{\prime \prime}$ & $5^{\circ} 37^{\prime} 19.9^{\prime \prime}$ & $47 \mathrm{~m}$ & \\
\hline BN 05 & $12^{\circ} 45^{\prime} 56.8^{\prime \prime}$ & $5^{\circ} 38^{\prime} 9.9^{\prime \prime}$ & $85 \mathrm{~m}$ & $\begin{array}{c}\text { Strat plan/ } \\
\text { N112/25NE } \\
\text { N105/23NE } \\
\text { N124/28NE }\end{array}$ \\
\hline BN 06 & $12^{\circ} 36^{\prime} 34.1^{\prime \prime}$ & $5^{\circ} 28^{\prime} 24.3^{\prime \prime}$ & $51 \mathrm{~m}$ & \\
\hline
\end{tabular}




\subsection{Lithological Descriptions}

We described the samples as follows:

- BN 01: The sandstone-like rock, black in color, with medium grain size has been observed all along the Mbuluzi River within Mbembika village. On the other side of the river, there is a small change in color (pinkish);

- BN 02: Rock of black color, with an average particle size, with different facies, impregnated with hydrocarbons;

- BN 03: We observe the presence of asphalt sand all along the Mbuluzi River and a little further the sand lines the bottom and the HCs float;

- BN 04: Dark colored rock, with medium grain size, impregnated with hydrocarbons staining the fingers, outcrops along the river at MABOMBOLO at the CEMA camp;

- BN 05: The rock has a finely granulated appearance and feel. On the other hand, the hardness, higher than that of glass, indicates the presence of quartz, confirmed by the vitreous black appearance of the grains, and allows us to conclude to the detrital or terrigenous nature of this rock. It is a quartz sandstone impregnated with hydrocarbon. Within the village of Mbinga;

- BN 06: A Side of the Timazimazi River; we observed heavy oil seepage on contact with the river. The more we remove a large surface part we find a coming of lighter bitumen; the latter constitutes a sort of completely black block, a little viscous in impregnation of sandstone [12] [13], it is bitumen (Figure 4), the images of some samples from the Study Area.

From the Mbuluzi River within the MBEMIKA villa to the Timazimazi River in the Sekulado village; we made a geological section oriented from the SW side to the NE, intersecting the following lithofacies: sandstone impregnated with hydrocarbons, calcareous sandstone impregnated with hydrocarbons and unimpregnated sandstone not impregnated (Figure 5).

The observations made in the section and the data in Table 1, allowed us to make the geological map below (Figure 6).

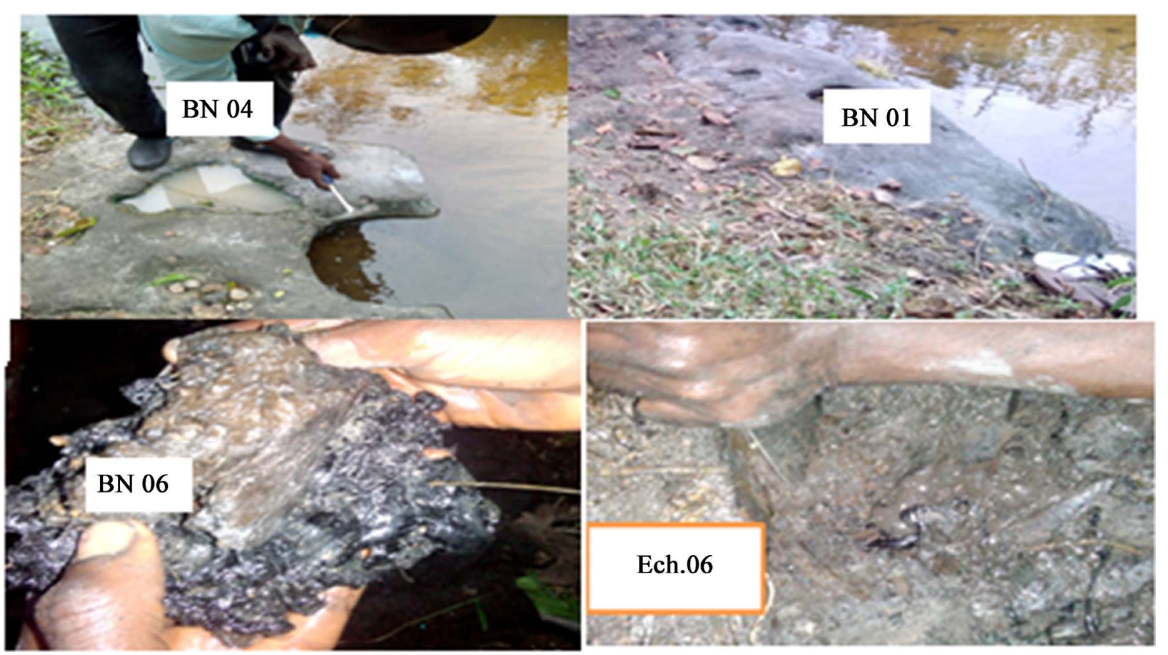

Figure 4. The images of some samples from the study area. 


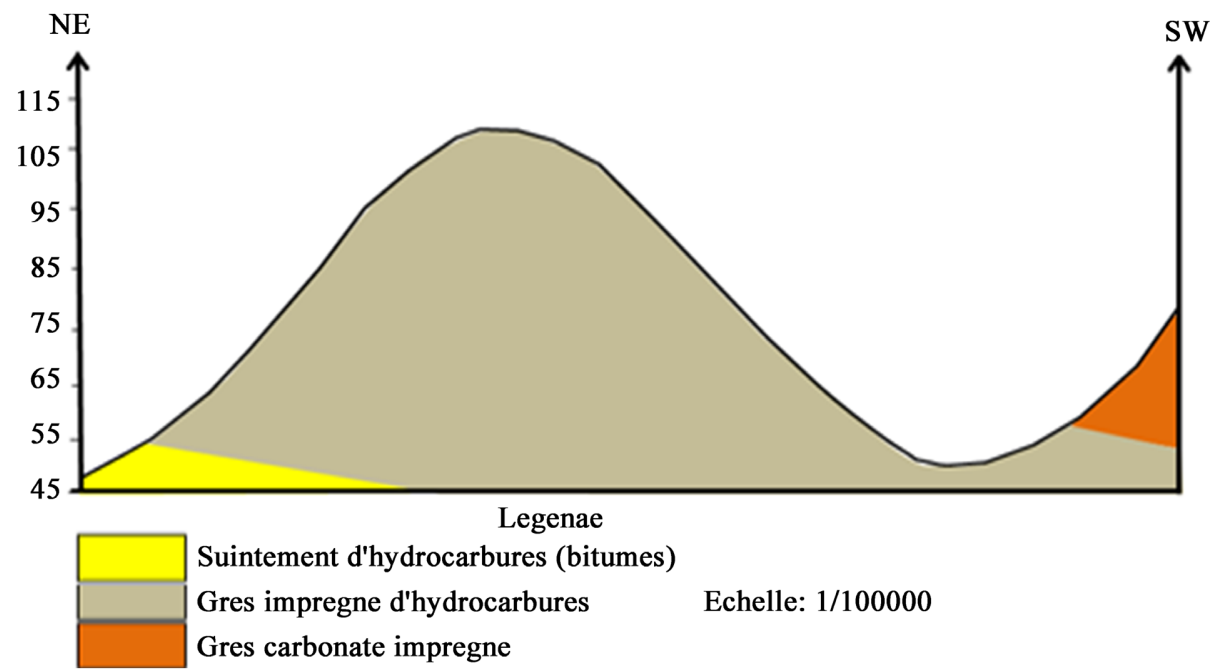

Figure 5. Geological section of the Lotshi block.

\section{Carte géologique de la zone d'étude}

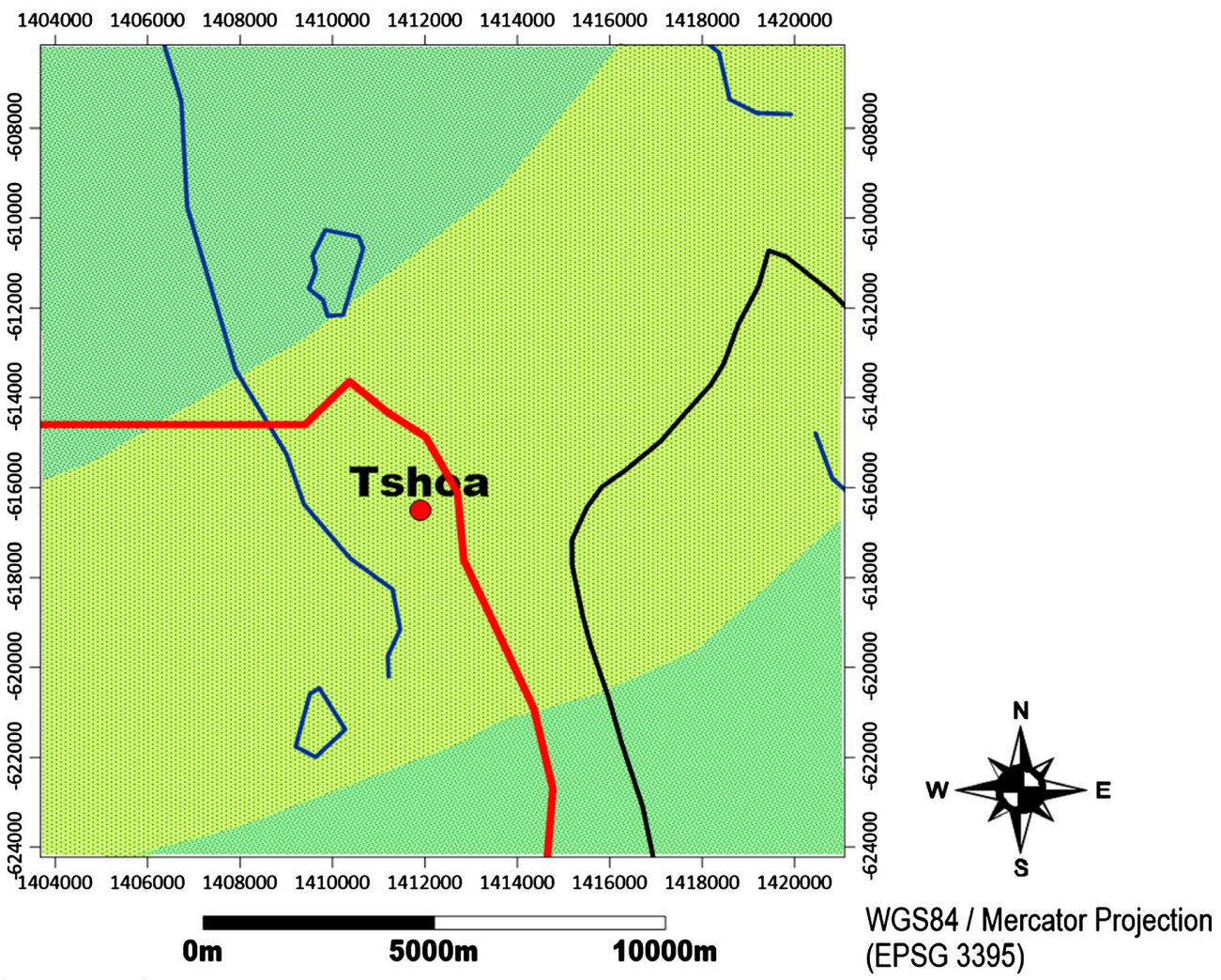

Print by DEKO et al.

\section{Légende}

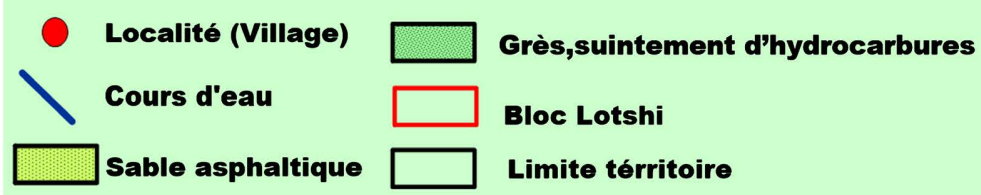

Figure 6. The geological map of the study area. 


\subsection{The Different Laboratory Analyzes}

We present the results of laboratory analyzes of rock samples and seeps collected in the field, in Lotshi and surroundings: - Three were selected for making the thin sections (BN 01, BN 04 and BN 05); - Two others for chemical analyzes (BN 02 and BN 05) at the CRGM laboratory; - Three samples (BN 01, BN 04 and BN 05) underwent XRD and XRF analyzes at the laboratory of the University of Liège in Belgium. The hydrocarbon binder contained in four samples of the sandstone rocks was extracted at the National Laboratory of Public Works (LNTP) of the Roads Office (OR) in Kinshasa.

\section{Macroscopic and Microscopic Description \\ Petrography study}

A.1 Macroscopic and microscopic description BN 01 The rock has a dark color with a medium grain size and it breaks down into platelets. It is impregnated with hydrocarbons and gives off a pungent odor, it is a detrital sedimentary rock (Figure 7). Under the microscope, sample BN 01 is observed to have small grains of xenomorphic quartz dispersed and embedded in a black or dark colored hydrocarbon binder where the rock is asphaltic quartz sandstone.

\section{Asphalt Mix Analysis}

The results of the binder extraction in the four samples are shown in Table 2.

We observe that the binder content varies between $12 \%$ and $25 \%$, an excessive
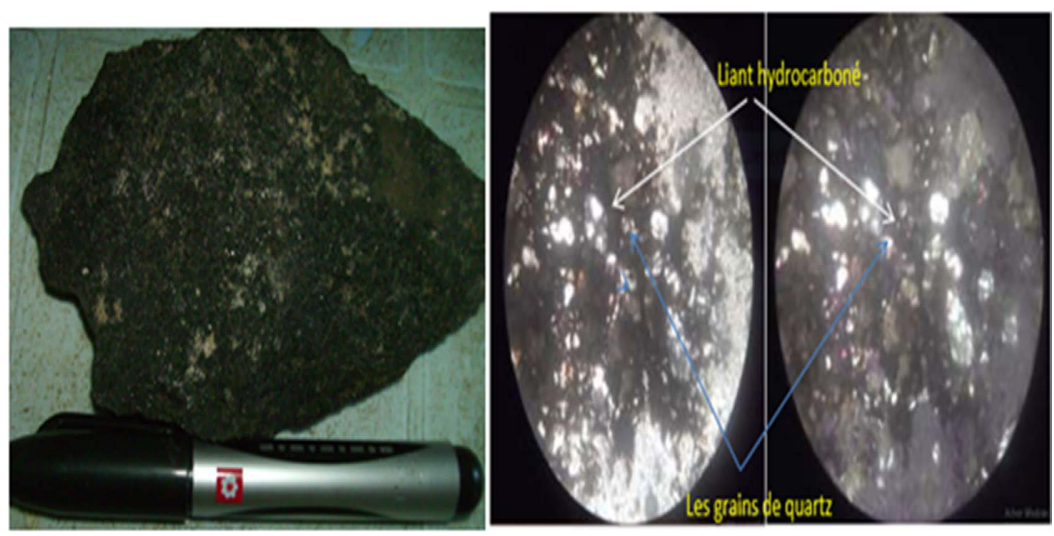

Figure 7. Macroscopic and microscopic view of sample BN 05.

Table 2. Percentages of the binder in the rock samples analyzed.

\begin{tabular}{ccccc}
\hline \multirow{2}{*}{ Désignation } & Lithofaciès & \multicolumn{2}{c}{ Poids en $\mathbf{g}$} & Résultats des essais en \% \\
\cline { 3 - 4 } & & $\mathbf{P}_{1}$ & $\mathbf{P}_{2}$ & 18 \\
\hline BN 04 & Sandstone & 202 & 171 & 20 \\
BN 01 & Sandstone & 208 & 173 & 12 \\
BN 05 & Sandstone & 200 & 178 & 25 \\
BN 06 & Sandstone & 206 & 165 & \\
\hline
\end{tabular}


content for the technical specifications in road construction.

An in-depth study of the various sites required to determine the possibility of exploitation in the future as was the case with the tar sands of Mavuma.

\section{Geochemistry}

We have the X-ray fluorescence method, carried out at the Clay, Geochemistry and Sedimentary Environment (AGEs) laboratory at the ULG and the volumetry, colorimetry, complexometry and gravimetry at the Center for Geological and Mining Research (CRGM).

\subsection{Fluorescence}

When a sample is bombarded with X-rays, it emits energy in the form of X-rays, the spectrum of which is characteristic of the composition of the sample. By analyzing this spectrum, we can deduce the elemental composition (the mass concentrations of elements).

The spectrometer used is ARL ${ }^{\mathrm{TM}}$ PERFORM'X from the ULG Sedimentary Petrology Laboratory (PETROSED).

\subsection{Preparation of Samples}

The material is dried at $40^{\circ} \mathrm{C}$, ground and sieved at $250 \mu \mathrm{m}$. The mass loss on heating is first determined. For this, the sample is heated at a temperature of $1000^{\circ} \mathrm{C}$ for 2 hours.

It is then decomposed by manual grinding, and then mixed at a proportion of $11 \times$ its mass $( \pm 0.0003)$ with the flow of borax $\mathrm{NaB}_{4} \mathrm{O}_{7} \cdot 10 \mathrm{H}_{2} \mathrm{O}$.

This compound has the properties of lowering the melting temperature. The 2 components (borax and sample) are then mixed manually and then subjected to fusion to ensure good homogeneity. The last step is to make beads that will be analyzed.

The elemental concentrations were obtained by carrying out a calibration against standards [14].

The results of the X-ray fluorescence are recorded in Table 3.

We observe the presence of several oxides constituting our samples analyzed in laboratories. Thus the presence of silica oxides is quite normal in our sandstone samples, because sandstone is formed by Quartz; however, oxides of aluminum, sodium and potassium come from weathering of igneous rocks.

High but variable values ( $26 \%$ to $31 \%$ ) of losses on fire are attributable to the hydrocarbon content of the rocks analyzed.

The presence of Cao proves that during the accumulation of organic matter, there were also living organisms.

\subsection{Volumetry, Colorimetry and Spectrophotometry}

Among the devices used we have:

- AR 2000 UV-visible spectrophotometer; 
Table 3. The results of the X-ray fluorescence are recorded in our three samples.

\begin{tabular}{cccc}
\hline Composition & Ech. BN 01 & Ech. BN 04 & Ech. BN 05 \\
\hline $\mathrm{SiO}_{2}$ & 64.61 & 50.83 & 20.66 \\
$\mathrm{TiO}_{2}$ & 1.92 & 0.35 & 0.32 \\
$\mathrm{Al}_{2} \mathrm{O}_{3}$ & 4.40 & 4.07 & 3.53 \\
$\mathrm{Fe}_{2} \mathrm{O}_{3}$ & 0.99 & 1.83 & 2.53 \\
$\mathrm{MnO}$ & 0.02 & 0.02 & 0.09 \\
$\mathrm{MgO}$ & 0.00 & 3.58 & 2.91 \\
$\mathrm{CaO}$ & 0.35 & 5.78 & 14.31 \\
$\mathrm{Na} 2 \mathrm{O}$ & 0.00 & 0.00 & 0.28 \\
$\mathrm{~K}_{2} \mathrm{O}$ & 2.00 & 2.23 & 0.83 \\
$\mathrm{P}_{2} \mathrm{O}_{5}$ & 0.02 & 0.05 & 0.08 \\
$\mathrm{LOI}$ & 25.70 & 31.27 & 54.45 \\
& & &
\end{tabular}

- Muffle furnace;

- Steamroom; and finally the digital scale.

According to the comparative study starting from the average obtained from the results of these two different laboratories (ULg and CRGM). We note that in the two columns there is an enrichment of silicon oxide which dominates starting and other with a small difference in value and followed by loss on ignition at the second position then come other oxides. So, we affirm that our samples taken during our geological survey in the field and analyzed, are in fact of asphaltic quartz sandstones.

\subsection{X-Ray Diffraction}

$\mathrm{X}$-ray diffractometry (XRD or $\mathrm{XRD}$ ) is an analysis technique based on the diffraction of X-rays by matter, particularly when it is crystalline (Table 4). X-ray diffraction is elastic scattering, that is to say, without loss of photon energy (unchanged wavelengths), which gives rise to interferences that are all the more markedas the matter is ordered. For non-crystalline materials, we speak more of diffusion.

Radiation used in a diffractometer has a wavelength of the order of $10-10 \mathrm{~m}$ (1 $\AA$ ), which is of the same order of magnitude as interatomic distances in solid materials.

\subsubsection{Preparation of Samples}

A total powder analysis was performed on each sample. The samples were dried in an oven at $30^{\circ} \mathrm{C}$, crushed manually in an agate bowl, and then sieved to recover fractions smaller than $250 \mu \mathrm{m}$. Pellets were then formed using metal supports for diffractometry.

\subsubsection{Equipment}

The diffractometer used is a D8-Eco from the Argiles, Geochemistry and 
Table 4. Comparative results of two laboratories (ULg and CRGM).

\begin{tabular}{ccc}
\hline $\begin{array}{c}\text { Composition } \\
\text { centésimale }\end{array}$ & $\begin{array}{c}\text { Résultat de l'échant. BN 01 } \\
\text { et BN 05 En Ulg }\end{array}$ & $\begin{array}{c}\text { Résultat de l'échantillon. BN 01 } \\
\text { et BN 05 au CRGM }\end{array}$ \\
\hline $\mathrm{SiO}_{2}$ & 42.64 & 71.85 \\
$\mathrm{Al}_{2} \mathrm{O}_{3}$ & 1.12 & 4.65 \\
$\mathrm{TiO}_{2}$ & 3.97 & 0.01 \\
$\mathrm{Fe}_{2} \mathrm{O}_{3}$ & 1.76 & 2.13 \\
$\mathrm{Na}_{2} \mathrm{O}$ & 0.06 & 0.16 \\
$\mathrm{MgO}$ & 1.46 & 0.75 \\
$\mathrm{CaO}$ & 7.33 & 1.38 \\
$\mathrm{~K}_{2} \mathrm{O}$ & 0.14 & 0.23 \\
$\mathrm{P}_{2} \mathrm{O}_{3}$ & 1.42 & 0.11 \\
$\mathrm{Humidité}$ & 0.05 & 5.5 \\
$\mathrm{LOI}$ & 40.08 & 18.45 \\
\hline
\end{tabular}

Sedimentary Environments (AGEs) Laboratory of the ULg.

\subsubsection{Analysis Method}

The powder sample is bombarded with X-rays obtained by bombarding a copper anode with a beam of electrons accelerated in a vacuum.

These X-rays in contact with the powder are reflected by each crystallite of the powder in an orientation in space. The reflected X-rays interfere with each other at various intensities [14].

The intensity detected is recorded as a function of the deflection angle $2 \theta$ (two-theta) of the beam. The curve obtained is called diffractogram or DRX spectrum.

By analyzing the XRD spectra obtained, it is possible to determine the mineral phases which constitute the powder. In fact, for certain angles of deviation $2 \theta$ of the beam, X-rays are detected. These are the "peaks" of the diffractogram. These angles of deviation are characteristic of the organization of atoms in the crystal lattice. In the other directions, we do not detect an X-ray, it is the baseline of the signal [15]. If we calculate the directions in which we have the signal, we see that we obtain a very simple law: $2 \cdot d \cdot \sin (\theta)=n \cdot \lambda$ where $\theta$ is half the angle of deviation, is not an integer called "diffraction order", $\lambda$ is the wavelength of X-rays and $d$ the distance between the planes of alignment of the atoms or interreticular distance. Subsequently, the EVA software was used to read the diffractograms and make it possible to identify the mineral phases, thanks to the parameter $\mathrm{d}$ (Table 5).

\subsection{RDX Results}

The mineral phases obtained in this DRX analysis are recorded in Table 6 and 
illustrated in the diffractograms of Figure 7.

Table 5. Main minerals determinable in the powder spectra.

\begin{tabular}{|c|c|c|c|}
\hline Minéraux & $2 \theta \cdot(\mathrm{CuKa})$ & $\mathrm{d}(\AA)$ & Facteur de correction \\
\hline Amphibole & $10.30-10.70$ & $8.59-8.27$ & 2.50 \\
\hline Analcite & $15.60-16.20$ & $5.68-5.47$ & 1.79 \\
\hline Anatase & $25.17-25.47$ & $3.54-3.50$ & 0.73 \\
\hline Anhydrite & $25.30-25.70$ & $3.52-3.46$ & 0.90 \\
\hline Apatite & $31.80-32.15$ & $2.81-2.78$ & 3.10 \\
\hline Aragonite & $45.65-46.00$ & $1.96-1.97$ & 9.30 \\
\hline Augite & $29.70-30.00$ & $3.00-2.98$ & 5.00 \\
\hline Barite & $28.65-29.00$ & $3.11-3.08$ & 3.10 \\
\hline Calcite & $29.25-29.60$ & $3.04-3.01$ & 1.65 \\
\hline Chlorite & $18.50-19.10$ & $4.79-4.64$ & 4.95 \\
\hline Clinoptilolite & $9.70-9.99$ & $9.11-8.84$ & 1.56 \\
\hline Cristobalite & $21.50-22.05$ & $4.13-4.05$ & 9.00 \\
\hline Dolomite & $30.80-31.15$ & $2.90-2.87$ & 1.53 \\
\hline Erionite & $7.50-7.90$ & $11.70-11.20$ & 3.10 \\
\hline Goethite & $36.45-37.05$ & $2.46-2.43$ & 7.00 \\
\hline Gypse & $11.30-11.80$ & $7.83-7.50$ & 0.40 \\
\hline Halite & $45.30-45.65$ & $2.00-1.99$ & 2.00 \\
\hline Hématite & $33.00-33.40$ & $2.71-2.68$ & 3.33 \\
\hline Kaolinite & $12.20-12.60$ & $7.25-7.02$ & 2.25 \\
\hline Feldspath-K & $27.35-27.79$ & $3.26-3.21$ & 4.30 \\
\hline Magnétite & $35.30-35.70$ & $2.54-2.51$ & 2.10 \\
\hline Micas & $8.70-9.10$ & $10.20-9.72$ & 6.00 \\
\hline Montmorillonite & $4.70-5.20$ & $18.80-17.00$ & 3.00 \\
\hline Palygorskite & $8.20-8.50$ & $10.70-10.40$ & 9.20 \\
\hline Phillipsite & $17.50-18.00$ & $5.06-4.93$ & 17.00 \\
\hline Plagioclase & $27.80-28.15$ & $3.21-3.16$ & 2.80 \\
\hline Pyrite & $56.20-56.45$ & $1.63-1.62$ & 2.30 \\
\hline Rhodochrocite & $31.26-31.50$ & $2.86-2.84$ & 3.45 \\
\hline Quartz & $26.45-26.95$ & $3.37-3.31$ & 1.00 \\
\hline Sépiolite & $7.00-7.40$ & $2.60-11.90$ & 2.00 \\
\hline Sidérite & $31.90-32.40$ & $2.80-2.76$ & 1.15 \\
\hline Talc & $9.20-9.55$ & $9.61-9.25$ & 2.56 \\
\hline Tridymite & $20.50-20.75$ & $4.33-4.28$ & 3.00 \\
\hline Gibbsite & $18.00-18.50$ & $4.93-4.79$ & 0.95 \\
\hline
\end{tabular}


Table 6. Mineral analyzes.

\begin{tabular}{cccc}
\hline Minéraux & Ech. 05 & Ech. 01 & Ech. 04 \\
Kaolinite & 1 & 1 & $<1$ \\
Micas & 1 & 2 & 2 \\
Chlorite & $<1$ & - & - \\
Anatase & $<1$ & $<1$ & - \\
Calcite & 34 & - & 2 \\
Dolomite & 15 & - & - \\
Hématite & 2 & - & 2 \\
Goethite & $<1$ & 2 & 66 \\
Quartz & 38 & 80 & 8 \\
Feldspaths-K & 3 & 15 & - \\
Plagioclase & 5 & - & \\
\hline
\end{tabular}

Rock samples from field work carried out in the Lotshi Exploratory Block and its surroundings have been subjected to microscopic, chemical and mineralogi$\mathrm{cal}$ analyzes by $\mathrm{X}$-ray diffraction in laboratories.

Overall, it should be noted that the lithological facies of the terrigenous type, sandstone, constitutes the bulk of rocks found in the field.

This rock, sometimes quartzose, sometimes carbonate, contains $12 \%$ to $25 \%$ of hydrocarbon binder.

The main mineralogical phases identified in this sandstone of hydrocarbon dysmigration are constituted by quartz, $\mathrm{K}$-feldspar, plagioclase, calcite, dolomite accompanied by impurities of micas and kaolinite.

\section{Interpretation of the Results}

Consists in interpreting the results of the rocks analyzed at the various laboratories (ULg and CRGM) are based on mineralogical, petrographic, petroleum and geochemical plans.

\subsection{On the Mineralogical and Petrographic Level}

Mineralogically and petrographically, the rocks in the study area have the following characteristics: 1) the dark or black colored hydrocarbon binder; 2) the presence of cracks on the surfaces of certain minerals; 3) quartz silts; 4) plagioclases with polysynthetic twins The petrographic characteristics can be explained as follows: - The presence of hydrocarbon binder is due to the dysmigration of hydrocarbons, that of cracks is caused by small cracks visible on the quartz minerals under the microscope and with the naked eye; - The abundance of quartz in our samples are considered a normal aspect because sandstone is made up mainly of 
silica, due to its resistance to weathering, by far the most frequent constituent of sandstone, quartz as a mineral would come from plutonic or metamorphic precursors of either volcanic rocks or recycled sandstone and finally plagioclase grains which, due to their fragility, cleavage and great alterability, rarely form more than $10 \%$ to $15 \%$ in sandstone [16].

\subsection{In Terms of Petroleum}

Given that the binder content varies between $12 \%$ and $25 \%$ in our samples, BN 01 , 04, 05 and 06 analyzed at the office des routes, we observe an excessive content which justifies the presence of impregnated hydrocarbons in the rocks. Surface area of the Lotshi Block, in addition, the reference content justifying the bitumens within the roads office is around $10 \%$. These found sandstones are part of the post-salt reservoir (Iabe/Vermelha) and were formed in a marine environment. The oil indices observed in this Block, sufficiently testify to the existence and the good functioning of the petroleum system, are a dysmigration of hydrocarbons generated from the pre-salt in the bedrock of Bucomazi, lacustrine and rich in type I organic matter. Indeed, the Vermelha sandstone constitutes the dirty post-salt reservoir in the Lotshi Block because of the terrigenous inputs coming from the littoral zone.

\subsection{In Terms of Civil Engineering Given that the Binder}

Content (bitumen) is too high compared to the reference content at the office of the route (OR) in our samples of the hydrocarbon indices, this sufficiently demonstrates a very strong impregnation of hydrocarbon in our samples. From which we can distinguish: Dense asphalt with grain sizes varying from dust (0/10 to $0 / 15)$ and $6 \%$ titer. In road development work; the latter is used as a wearing course with the percentage of bitumen greater than GB (gravel bitumen). Severe bitumen, with grain size between (0/15 to $0 / 20)$ with a content of $4 \%$ to $5 \%$. It is used as the first layer of asphalt. Therefore, a grade between 12 and 25 in our rock samples remains tangible evidence of active surface index and the functioning of the petroleum system in our study area and surroundings.

\section{Conclusions and Suggestions}

\subsection{Conclusions}

In the present research on the characterization of the hydrocarbon showings in the Lotshi block and virons, our objectives are to know the density of the showings, to determine the major lithofacies of the zone, and to give the interest presented by these ma rocky materials impregnated with hydrocarbons. After analysis of the samples brought back from the field, the results obtained are thus summarized:

- On the mineralogical level: quartz, k-feldspar, plagioclase, calcite and dolomite are the dominant minerals.

Accessory phases of minerals such as micas and kaolinite have also been identified.

- Lithologically: Dark to pinkish sandstones, with angular or sub-angular grains 
of medium size and sometimes showing cracks, constituting the bulk of the sedimentary rocks of the study site;

- On the petroleum side: The sandstone rock of Lotshi and the surrounding areas are impregnated with hydrocarbons. It titrates between $12 \%$ and $25 \%$ of hydrocarbon binder.

It is clear that the area is dominated by detrital sedimentary rocks precisely of asphaltic quartz sandstone, and also the presence of carbonate sandstone, the density of the suggested indices that the region is characterized by enormous tectonic movements.

\subsection{Suggestions}

- Intensify fieldwork (geological survey) on the entire Lotshi Block by taking not only rock samples but also related structural measurements;

- To characterize the rocks that can serve as a cover (argillites, salts, marls, etc.) and reservoirs, insisting on closure. This work can begin with the reprocessing and reinterpretation of log data from wells drilled in the Lotshi;

- To determine, by drilling wells a few meters deep, the quantity of impregnated sandstone with a view to considering their use in civil engineering (use in linear structures).

\section{Conflicts of Interest}

The authors declare no conflicts of interest regarding the publication of this paper.

\section{References}

[1] et Richards, A. (2002) Quantitative Seismology. 2nd Edition, University Science Books, Sausalito.

[2] Westhondo, D. (2013) Introductory Oil Exploration Course, G3 Oil and Gas/Unikin. $92 \mathrm{p}$.

[3] Ashton, P.R. (2010) Exploration effective des zones distantes du Bassin Côtier, RDC: Antécédent historique sur le block Nganzi; Exposé pour le compte de SOCO International plc.

[4] Dunham, R.J. (1970) Stratigraphy Reefs versus Ecology Reefs. American Association of Petroleum Geologists Bulletin, 54, 1931-1932. https://doi.org/10.1306/5D25CC49-16C1-11D7-8645000102C1865D

[5] Gaffney, Cline \& Associates (Consultants) Pte., Ltd. (1988) Study on the Reserves of the Coastal Basin of the Republic of Zaire, Study Report, 16 p.

[6] Zaire, C. (1990) Study Report of the Identification of Six Prospects in the Lemba Ditch from the Interpretation of Seismic Data.

[7] Sonahydroc, S.A. (2013) Report Régional GeoChemistry-Analyses. SONAHYDROC, Société Nationale des Hydrocarbures du Congo.

[8] Surestream, R.D.C. (2010) Surestream RDC Sarl; Exploration of the Petroleum Potential of the YEMA and Matamba-Makanzi Blocks; COPE 1 Presentation.

[9] Baeyens, J. (1938) Les sols de l'Afrique centrale, spécialement du Congo Belge. Institut National pour l'Etude Agronomique du Congo belge, $102 \mathrm{p}$.

[10] et Ernest Vander Linden, D. (1951) Bas-Congo, Vital Artery of Our Colony. 2nd Edi- 
tion, Goemare, Brussels, $87 \mathrm{p}$.

[11] Zhu, X.M., et al. (2013) Deformational Mechanism and Tectonic Evolution of Mesozoic-Cenozoic Nonmarine Basins from Bohai Bay Basin-China. SUST Journal of Engineering and Computer Science (JECS), 15, pages.

[12] Ginsburg, R.N. (1955) Recent Stromatolitic Sediment from South Florida. Journal of Paleontology, 29, 723-724.

[13] Guillemot, J. (1964) Petroleum Geology Course. Course of the National Higher School of Petroleum and Engines. Technip Publishing Company, $321 \mathrm{p}$.

[14] Folk, R.L. (1980) Petrology of Sedimentary Rocks. Hemphill, Austin, 182 p.

[15] Hardy, R. and Tucker, M. (1988) Téchniques in Sedimentology, X-Ray Powder Diffraction of Sediments.

[16] Boulvain, F. (2020) Elements of Sedimentology and Sedimentary Petrology, Laboratory. Sedimentary Petrology. University of Liège, Belgium, 173 p. 